\title{
Analysis of differentially co-expressed genes based on microarray data of hepatocellular carcinoma
}

\author{
Y. WANG ${ }^{1, *}$, T. JIANG ${ }^{2, *}$, Z. LI², L. LU², R. ZHANG ${ }^{2}$, D. ZHANG ${ }^{2}$, X. WANG ${ }^{2, *}$, J. TAN TAN $^{3, *}$ \\ ${ }^{1}$ Department of Oncology, the Eighty-fifth Military Hospital, Shanghai, 200052, China; ${ }^{2}$ Department of Surgical Oncology, Jingdu Hospital, \\ Nanjing, 210002, China; ${ }^{3}$ Chinese PLA General Hospital No.28, Fuxing Road, Beijing, 100853, China
}

${ }^{*}$ Correspondence: xuanwang2016vip@163.com,jwt2016vip@163.com

${ }^{*}$ Contributed equally to this work.

Received August 1, 2016/ Accepted October 22, 2016

\begin{abstract}
Hepatocellular carcinoma (HCC) is the third leading cause of cancer related death worldwide. Although great progress in diagnosis and management of HCC have been made, the exact molecular mechanisms remain poorly understood. The study aims to identify potential biomarkers for HCC progression, mainly at transcription level. In this study, chip data GSE 29721 was utilized, which contains 10 HCC samples and 10 normal adjacent tissue samples. Differentially expressed genes (DEGs) between two sample types were selected by t-test method. Following, the differentially co-expressed genes (DCGs) and differentially co-expressed Links (DCLs) were identified by DCGL package in R with the threshold of $\mathrm{q}<0.25$. Afterwards, pathway enrichment analysis of the DCGs was carried out by DAVID. Then, DCLs were mapped to TRANSFAC database to reveal associations between relevant transcriptional factors (TFs) and their target genes. Quantitative real-time RT-PCR was performed for TFs or genes of interest. As a result, a total of 388 DCGs and 35,771 DCLs were obtained. The predominant pathways enriched by these genes were Cytokine-cytokine receptor interaction, ECM-receptor interaction and TGF- $\beta$ signaling pathway. Three TF-target interactions, LEF1-NCAM1, EGR1-FN1 and FOS-MT2A were predicted. Compared with control, expressions of the TF genes EGR1, FOS and ETS2 were all up-regulated in the HCC cell line, HepG2; while LEF1 was down-regulated. Except NCAM1, all the target genes were up-regulated in HepG2. Our findings suggest these TFs and genes might play important roles in the pathogenesis of HCC and may be used as therapeutic targets for HCC management.
\end{abstract}

Key words: hepatocellular carcinoma, differential co-expression, transcription factor, LEF1, EGR1, FOS

Hepatocellular carcinoma (HCC) is the seventh most common malignancy and the third leading cause of cancerrelated death worldwide [1]. Annually, about 0.25-1 million individuals are estimated to be newly diagnosed with HCC. It is most frequent in some developing countries in sub-Saharan Africa and far eastern Asia, where hepatitis B virus (HBV) and hepatitis $\mathrm{C}$ virus (HCV) infections are endemic and food contamination with Aflatoxin B1 is consumed. Since HCC has caused a major health problem worldwide [2], many studies have been performed to explore the underlying molecular mechanisms of HCC.

Based on previous findings, epidermal growth factor (EGF) signaling is one of the most thoroughly evaluated signaling pathways in human HCC. Evidence shows that up-regulation of EGF is highly associated with HCC [3]. In addition, EGF receptor (EGFR) has anti-proliferative and pro-apoptotic ef- fects in human HCC xenografts [4]. Mitogen Activated Protein Kinase (MAPK) pathway plays key roles in HCC development, which regulates cell growth stimulation and involves in a number of receptors, such as EGFR $[5,6]$, hepatocyte growth factor receptor (HGFR) [7, 8], and insulin-like growth factor receptor (IGFR) [9]. Moreover, alterations of AKT and PETN, two important genes in PI3K/AKT/mTOR signaling pathway, have been demonstrated to be associated with HCC $[10,11]$. Despite these significant findings, comprehensive regulation mechanisms on HCC pathogenesis remains obscure, especially about the transcription factor (TFs) information.

Previously, Stefanska et al established a chip microarray dataset to examine the landscape of promoter DNA methylation in HCC [12]. Nonetheless, broad information could be extracted in this dataset to elucidate HCC etiology. Therefore, we utilized their dataset, GSE29721, to carry out a series of 
bioinformatics analyses, such as differential expression analysis, enrichment analysis and TF-target prediction. Importantly, the identified key TFs and genes were validated via real-time quantitative reverse transcriptase-polymerase chain reaction (qRT-PCR). The study aimed to identify crucial biomarkers of HCC prognosis and elucidate potential transcriptional regulation mechanisms in HCC progression.

\section{Materials and methods}

Gene expression data of HCC. The GSE29721 [12] chip expression data were downloaded from the Gene Expression Omnibus (GEO, http://www.ncbi.nlm.nih.gov/geo/) database based on the GPL570 (HG-U133_Plus_2) Affymetrix Human Genome U133 Plus 2.0 Array platform. There were a total of 20 samples in this dataset, consisting of 10 cancerous and 10 normal adjacent tissue samples from $10 \mathrm{HCC}$ patients. Then the annotation files of these samples were downloaded.

Analysis of differential co-expression. The chip data were normalized by the Robust Multichip Average (RMA) method [13] implemented in Affy package of R. The t-test in Linear Models for Microarray Analysis (limma, http:// www.bioconductor.org/packages/release/bioc/html/limma. html) package [14] of R software was used to calculate the differentially expressed genes (DEGs), with the thresholds of $\mid \log _{2}$ fold change $(\mathrm{FC}) \mid>1.0$ and $\mathrm{P}$ value $<0.05$. Differential co-expression analysis (DCEA) could detect the expression alterations in a gene pair under two different conditions, which contributes to the reveal of transcriptional mechanisms. The DCGL is a package in R includes 5 DCEA methods to select the differentially co-expressed genes (DCGs) and differentially coexpressed links (DCLs) [15]. After DEG selection, the DCGs and DCLs were identified by DCe, DCp and DCsum of DCGL package in R based on expression data of these DEGs. During this selection, $\mathrm{q}<0.25$ was considered as the threshold.

Pathway enrichment analysis of DCGs. The Kyoto Encyclopedia of Genes and Genomes (KEGG, http://www.genome. $\mathrm{jp} / \mathrm{kegg} /$ pathway.html) pathway database is a relatively common and comprehensive database that contains a variety of biochemical pathways [16]. In the present study, the online tool Database for Annotation, Visualization and Integration Discovery (DAVID, http://david.abcc.Ncifcrf.gov/) was used to perform KEGG pathway enrichment analysis for DCGs [17].

Construction of HCC-related transcriptional regulation network. TRANSFAC [18] is a database related to TFs and their genomic binding sites on DNA-binding profiles. It composes of SITE, GENE, FACTOR, CLASS, MATRIX, CELLS, METHOD and REFERENCE and so on. All relations between human TFs and target genes in TRANSFAC were downloaded and compiled, which included a total of 298 TFs and 6,458 relations.

The DCLs were mapped to the known relations between human TFs and its target genes, and the common relations were screened out. Then the TFs and DCGs in the common relations were identified. Furthermore, a network was constructed using Cytoscape [19] software.

Gene expression validation in vitro. The human $\mathrm{HCC}$ cell line HepG2 $(n=2)$, and the normal HCC LO2 cell line $(n=2)$ were used in the validation experiment. They were bought from cell bank of the Chinese Academy of Sciences, and were cultured in DMEM medium supplemented with $10 \%$ fetal bovine serum (FBS) and 1\% penicillin-streptomycin (pc) antibiotics (Thermo, USA), at $37^{\circ} \mathrm{C}$ in a humidified atmosphere with $5 \% \mathrm{CO}_{2}$.

Total RNAs were isolated from each sample based on RNAiso Plus kit following the manufacturer's instructions (Takara, China). Gene expressions of interest were validated by qRT-PCR. In brief, following RNA purification, the cDNA synthesis was performed by the RNA reverse transcription kits (Takara, China). After the first cDNA was generated, the SYBR green qPCR was performed using ABI prism 7900 (Applied Biosystems). The relative expression was analyzed by the $2^{-\triangle \Delta C T}$ method. Human GAPDH gene was used as internal reference. Primer sequences of genes were listed in Table 1. The experiment was technically repeated for three times.

Statistical analysis. Data were presented as "mean \pm SEM". Independent $t$ test was used to determine significant differences, and $\mathrm{P}<0.05$ was set as the threshold. Statistical analysis was performed by the software of SPSS (22.0), and the graph software was the GraphPad Prism 5.

\section{Results}

Differential co-expression analysis. Under the criteria of $\left|\log _{2} \mathrm{FC}\right|>1.0$ and P value $<0.05$, totally 1,755 DEGs were obtained. In addition, a group of 388 DCGs and 35,771 DCLs were identified by DCGL package with $\mathrm{q}<0.25$.

Table 1. Primer sequences of genes of interest.

\begin{tabular}{ll}
\hline Genes & Primer sequence \\
\hline \multirow{2}{*}{ LEF1 } & F:5'-AAATAAAGTGCCCGTGGTGC-3' \\
& R:5'-TGAGGATGGGTAGGGTTGCC-3' \\
EGR1 & F:5'-CTGACCGCAGAGTCTTTTCCTG-3' \\
& R:5'-TGGGTGCCGCTGAGTAAATG-3' \\
FOS & F:5'-TGCCTAACCGCCACGATG-3' \\
& R: 5'-TGCGGGTGAGTGGTAGTAAGAG-3' \\
ETS2 & F:5'-GTGGACCTATTCAGCTGTGG-3' \\
& R:5'-TTCCCCGACGTCTTGTGGAT-3' \\
FN1 & F:5'-GAGCTGCACCTGTCTTGGGAAC-3' \\
& R:5'-GGAGCAAATGGCACCGAGATA-3' \\
NCAM1 & F:5'-AGATGAGGGCACTTATCGCT-3' \\
& R:5'-GATGGTAGGTGGCACATTCA-3' \\
MT2A & F:5'-AAAGGGGCGTCGGACAAGT-3' \\
& R:5'-TAGCAAACGGTCACGGTCAG-3' \\
GAPDH & F:5'-TGACAACTTTGGTATCGTGGAAGG-3' \\
& R:5'-AGGCAGGGATGATGTTCTGGAGAG-3' \\
\hline
\end{tabular}




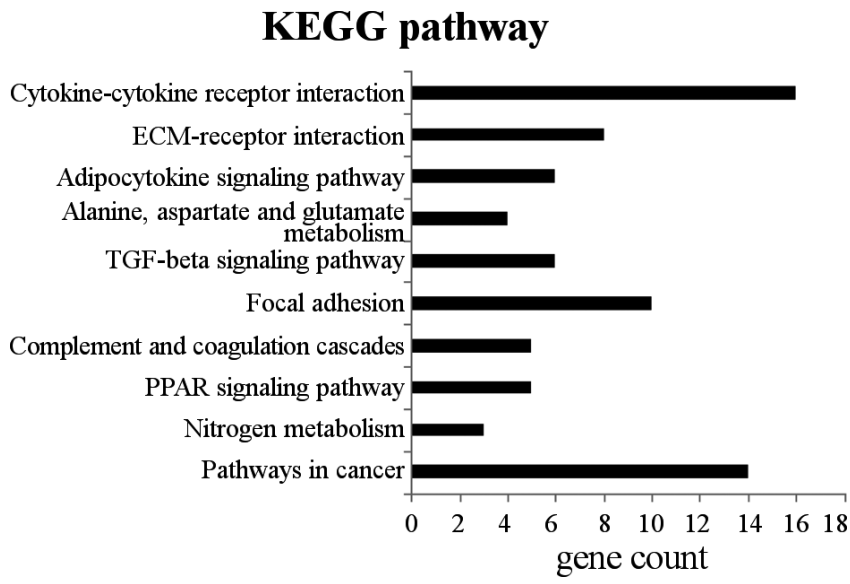

Figure 1. The significant pathways of differentially co-expressed genes (DCGs) (Top ten ranked by significant $P$ values). Abscissa represents the number of genes enriched in a pathway, and the vertical axis represents the name of the pathway.

Biological pathways closely related to HCC. The 388 DCGs were performed pathway enrichment analysis by DAVID, and the top 10 pathways ranked by the significance $(\mathrm{P}<$ $0.05)$ were listed in Figure 1, such as the Cytokine-cytokine receptor interaction, ECM-receptor interaction, Adipocytokine signaling pathway, Alanine, aspartate and glutamate metabolism, TGF- $\beta$ signaling pathway, Focal adhesion, PPAR signaling pathway, Complement and coagulation cascades, Nitrogen metabolism and Pathways in cancer.

Analysis of transcriptional regulation. The 35,771 DCLs were mapped to the known relations of human TFs and target genes. As a result, the TF-target was consisted of 25 TFs and 388 DCGs (Supplementary Figure 1). Among the network, four TFs were highlighted with multiple targets, such as EGR1, LEF1, FOS and ETS2. Notably, three known human TF-target interactions of EGR1-FN1, FOS-MT2A and LEF1-NCAM1 were predicted (Table 2).

Gene validations. As expected, gene expressions of four TFs were all consistent with predictions: LEF1 was significantly decreased ( $\mathrm{P}<0.01$, Figure $2 \mathrm{~A})$, EGR1, FOS and ETS2 were significantly up-regulated $(\mathrm{P}<0.001, \mathrm{P}<0.001$ and $\mathrm{P}<$ 0.01 , respectively, Figure $2 \mathrm{~B}-\mathrm{D})$. NCAM1, the predicted target of LEF1, was significantly down-regulated $(\mathrm{P}<0.01$, Figure $2 \mathrm{E}) ; \mathrm{FN} 1$, the predicted target of EGR1, was significantly up-regulated $(\mathrm{P}<0.01$, Figure $2 \mathrm{~F})$; and $M T 2 A$, the predicted target of FOS, was increased in HCC samples, however without significant difference (Figure $2 \mathrm{G}$ ).

\section{Discussion}

In this study, we used DCGL method to perform the differential co-expression analysis of HCC microarray data. Finally a total of 388 DCGs and 35,771 DCLs were obtained. Pathway enrichment analysis of DCGs indicated that they were mainly enriched in cytokine-cytokine receptor interaction, ECM-receptor interaction, TGF- $\beta$ signaling pathway, PPAR signaling pathway, etc., which were in accordance with previous studies [20,21].

Among these enriched pathways, TGF- $\beta$ signaling pathway was the most predominant one. TGF- $\beta 1$ is a tumor suppressor with true haploinsufficiency [22]. Disruption of TGF- $\beta 1$ signaling is associated with the acceleration of hepato-carcinogenesis in $c-M y c / T G F-\alpha$ transgenic mice [23]. TGF- $\beta 1$
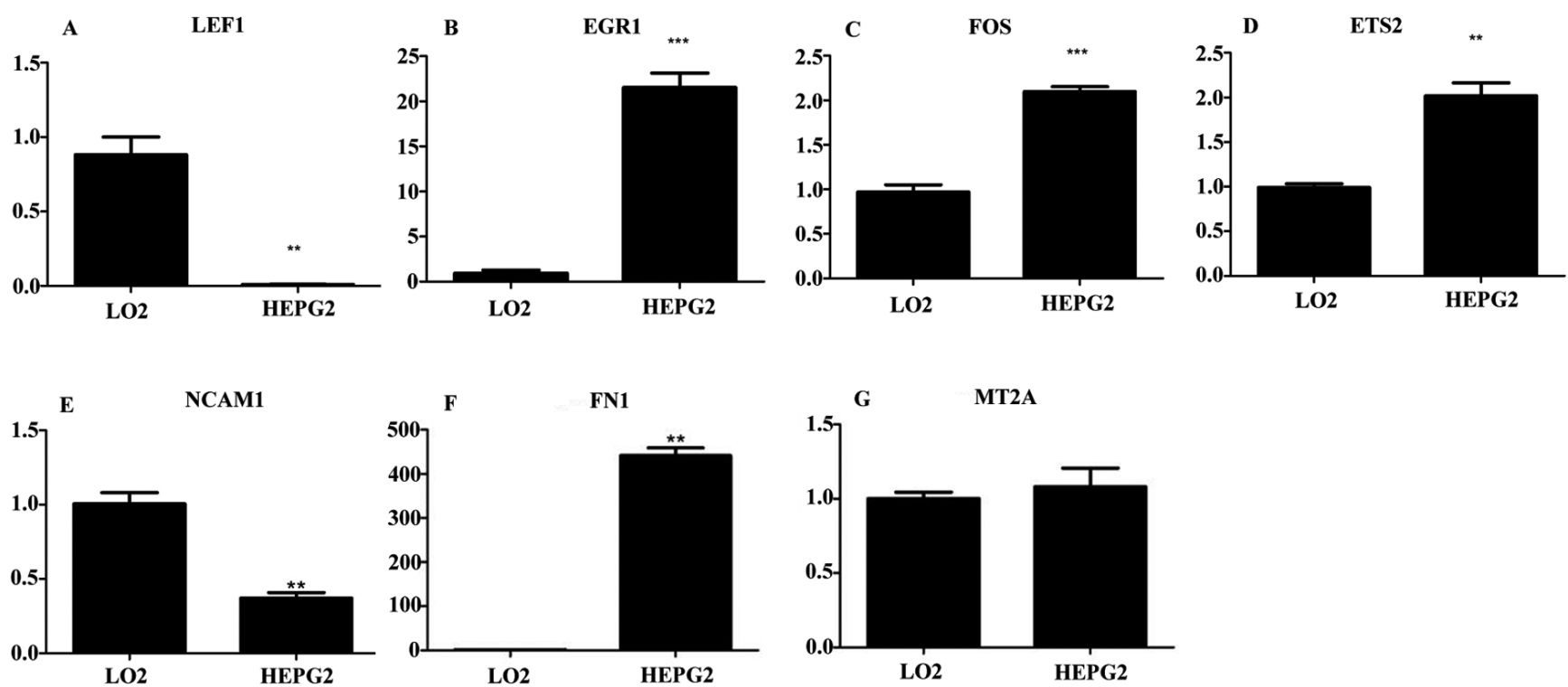

Figure 2. Relative gene expressions of four transcription factors and three targets using real-time qRT-PCR. A: LEF1; B: EGR1; C: FOS; D: ETS2; E: NCAM1; F: FN1; G: MT2A. ${ }^{\star}$ represents P-value $<0.01$ and ${ }^{\star *}$ represents P-value $<0.001$. 
Table 2. Crucial transcriptional regulation relations for DCLs

\begin{tabular}{lccccc}
\hline TF & Target & cor.1 & cor.2 & type & cor.diff \\
\hline LEF1 & NCAM1 & -0.7523 & -0.02114 & same signed & 0.731155 \\
EGR1 & FN1 & 0.825129 & 0.109075 & same signed & 0.716054 \\
FOS & MT2A & 0.709549 & 0.097272 & same signed & 0.612277 \\
\hline
\end{tabular}

TF refers to transcription factor; Target refers to target gene; cor.1, cor2 represent the maximum absolute correlation coefficient of TF and target, respectively; type refers to the type of relationship: same signed, diff signed and switched opposites; cor.diff means absolute difference of cor.1 and cor.2.

is over-expressed in a number of HCCs and its expression correlates with HCC dedifferentiation [24]. Moreover, TGF- $\beta 1$ may be considered as a prognostic marker for HCC because the serum levels of TGF- $\beta 1$ are closely associated with poor prognosis and could increase tumor angiogenesis [25]. The mechanisms of HCC induced by TGF- $\beta$ are dependent on the effects of TGF- $\beta$ on fibrogenesis. Continuous TGF- $\beta$ secretion could support neo-angiogenesis, loss of E-cadherin-dependent adhesion, and $\beta 1$-integrin activation that may favor the formation of tumor metastases $[25,26]$. TGF- $\beta$ signaling induces epithelial to mesenchymal transition (EMT), which promotes cell migration and invasiveness [27]. Notably, TGF- $\beta$ signaling dysfunction occurs in STAT3/Oct4-positive HCC cells [28], suggesting this pathway is vital for HCC progression. Based on our enrichment result, it might be inferred that altered gene expressions might result in the disturbance of TGF- $\beta$ signaling pathway, which might further promote the HCC development.

In addition, our study predicted $3 \mathrm{TF}$-Target interactions, including LEF1-NCAM1, EGR1-FN1, and FOS-MT2A (Supplementary Figure 1).

Lymphoid enhancing factor 1 (LEF1) is a TF mediating Wnt/b-catenin signaling by binding to its target gene neural call adhesion molecule 1 (NCAM1). Hepatocyte growth factor (HGF), a secretory protein that plays important roles in cancer growth and metastasis, is reported to induce expression of LEF1 in liver and breast cancer cell lines [29, 30]. Wnt/bcatenin pathway is another important pathway for tumor growth and invasion. When Wnt signaling is activated by external stimuli, b-catenin is accumulated in cytoplasm and then translocated to nuclei, where the TFs of T-cell factor/LEF (TCF/LEF) family members bind to their targets [31]. LEF1 is over-expressed in multiple types of cancer such as liver cancer [32]. Overexpression of LEF1 enhances tumor invasion by inducing epithelial to EMT [33]. LEF1 has been reported to be transcriptional activated by b-catenin/TCF 4 complex and it is thought to be an amplifier of Wnt/b-catenin signaling [34]. Interestingly, in gastric cancer, the transcriptional relationship of LEF1-NCAM1 is predicted based on the GeneChip Human Exon 1.0 ST microarray data, and their expressions are validated by qRT-PCR (LEF1 increased, while NCAM1 decreased) [35]. Although the LEF1-NCAM1 regulation in HCC has been recorded in the TRANSFAC database, there are few studies validated their expressions. Based on our qRT-PCR experiments, the LEF1 TF gene was significantly down-regulated as predicted, while its target NCAM1 was also remarkably down-regulated, suggesting they might have a positive regulation relationship.

Early growth response 1 (EGR1), a family member of zincfinger TFs, also can be activated by HGF [36]. EGR1 has been implicated in the regulation of a number of genes involved in inflammation, differentiation, growth, and development [37]. It seems that EGR1 is particularly important in the process of tumor angiogenesis. For instance, a study has shown that silencing of EGR1 expression with DNA zymes significantly inhibits breast cancer growth and angiogenesis in vivo [38]. Furthermore, EGR1 has been discovered essential for growth or differentiation [20]. The FN1 gene encodes a fibronectin related to cell adhesion and migration processes. Reportedly, gene expression of $F N 1$ is reduced in HCC tumor samples [39]. It is found after HGF treatment, the TF of EGR1 is induced in primary hepatocytes, and additionally, it is identified as a target gene of MET, which promotes tumor progression and metastasis of HCC [40]. Notably, FN1 is also predicted as a target of MET [40]. However, there are few studies reporting the targeting relationship between EGR1 and FN1. Based on our findings, FN1 was predicted as a target of EGR1, and both of them were significantly up-regulated in HepG2 cell line via qRT-PCR. This suggested that EGR1 might positively regulate gene expression of FN1.

The FOS proteins are basic region-leucine zipper (bZIP) TFs that bind to Jun or other bZIP proteins and create the activator protein 1 (AP-1) dimer complex to regulate gene expression [41]. Especially the c-Fos, a well-established oncogene, is considered to play a critical role in tumorigenesis, proliferation and metastasis in HCC development $[27,42,43]$. MT2A (Metallothionein 2A) is a member of metallothioneins (MTs) that belong to the cysteine-rich intracellular proteins. A microarray profiling shows MT genes are induced by the GSK343, an anti-HCC agent; and additionally, the induction is validated via western blot experiments [44], indicating MT2A might have an inhibitive effect on HCC progression. Unfortunately, researches about FOS-MT2A transcriptional regulation in HCC are rare. In our study, this targeting regulation was predicted and both of them were validated to be up-regulated in the HCC cell lines, suggesting FOS-induced MT2A might prevent HCC development.

ETS2 (ETS Proto-Oncogene 2) is a TF that controls genes associated with apoptosis. Mixed-lineage leukemia (MLL) is a critical regulator affecting cell cycle-correlated event. It is 
validated via ChIP assays that the MLL-ETS2 complex binding to $M M P 1$ and $M M P 3$ promoters, which is induced by the activation of HGF-MET pathway, could promote the cell invasion in HCC [45]. This indicates that ETS2 has an important role in HCC development. Based on our results, the up-regulated ETS2 was a crucial TF in HCC cell line.

Although gene expressions of these key TFs and targets were validated via qRT-PCR, the precise targeting interactions were not convinced. Further experiments with dual luciferase reporter system need to be conducted. In addition, the sample size was relatively small in either of the microarray dataset or the cell lines of validation experiment. Despite these limitations, the study would shed light on a better understanding of transcriptional mechanism on HCC progression, and provide potential therapeutic biomarkers for the prognosis.

In conclusion, this study identified several key TFs and their targets that might be used as prognostic biomarkers of HCC. However, the detailed targeting relationships still need to be further investigated via dual luciferase reporter system.

Supplementary information is available in the online version of the paper.

\section{References}

[1] BEASLEY RP, LIN C-C, HWANG L-Y, CHIEN C-S. Hepatocellular carcinoma and hepatitis B virus. A prospective study of 22707 men in Taiwan. Lancet 1981; 318: 1129-1133. https:// doi.org/10.1016/S0140-6736(81)90585-7

[2] BRUIX J, SHERMAN M, LLOVET JM, BEAUGRAND M, LENCIONI R et al. Clinical management of hepatocellular carcinoma. Conclusions of the Barcelona-2000 EASL conference. J Hepatol 2001; 35: 421-430. https://doi.org/10.1016/ S0168-8278(01)00130-1

[3] VILLANUEVA A, CHIANG DY, NEWELL P, PEIX J, THUNG $S$ et al. Pivotal role of mTOR signaling in hepatocellular carcinoma. Gastroenterology 2008; 135: 1972-1983. https://doi. org/10.1053/j.gastro.2008.08.008

[4] VILLANUEVA A, NEWELL P, CHIANG DY, FRIEDMAN SL, LLOVET JM. Genomics and signaling pathways in hepatocellular carcinoma. Semin Liver Dis 2007; 27: 55-76. https://doi. org/10.1055/s-2006-960171

[5] SCHIFFER E, HOUSSET C, CACHEUX W, WENDUM D, DESBOIS-MOUTHON C et al. Gefitinib, an EGFR inhibitor, prevents hepatocellular carcinoma development in the rat liver with cirrhosis. Hepatology 2005; 41: 307-314. https:// doi.org/10.1002/hep. 20538

[6] BERASAIN C, PERUGORRIA MJ, LATASA MU, CASTILLO J, GONI $S$ et al. The epidermal growth factor receptor: a link between inflammation and liver cancer. Exp Biol Med (Maywood) 2009; 234: 713-725. https://doi. org/10.3181/0901-MR-12

[7] TAVIAN D, DE PETRO G, BENETTI A, PORTOLANI N, GIULINI SM et al. u-PA and c-MET mRNA expression is coordinately enhanced while hepatocyte growth factor mRNA is down-regulated in human hepatocellular carcinoma. Int J
Cancer 2000; 87: 644-649. https://doi.org/10.1002/1097-0215(20000901)87:5<644::AID-IJC4>3.0.CO;2-W

[8] KAPOSI-NOVAK P, LEE J-S, G MEZ-QUIROZ L, COULOUARN C, FACTOR VM et al. Met-regulated expression signature defines a subset of human hepatocellular carcinomas with poor prognosis and aggressive phenotype. J Clin Invest 2006; 116: 1582-1595. https://doi.org/10.1172/JCI27236

[9] CARDILLO MR, MONTI S, DI SILVERIO F, GENTILE V, SCIARRA $F$ et al. Insulin-like growth factor (IGF)-I, IGFII and IGF type I receptor (IGFR-I) expression in prostatic cancer. Anticancer Res 2003; 23: 3825-3835.

[10] BOYAULT S, RICKMAN DS, DE REYNI S A, BALABAUD C, REBOUISSOU $S$ et al. Transcriptome classification of HCC is related to gene alterations and to new therapeutic targets. Hepatology 2007; 45: 42-52. https://doi.org/10.1002/ hep. 21467

[11] PEYROU M, BOURGOIN L, FOTI M. PTEN in liver diseases and cancer. World J Gastroenterol 2010; 16: 4627-4633. https://doi.org/10.3748/wig.v16.i37.4627

[12] STEFANSKA B, HUANG J, BHATTACHARYYA B, SUDERMAN M, HALLETT $M$ et al. Definition of the landscape of promoter DNA hypomethylation in liver cancer. Cancer Res 2011; 71: 5891-5903. https://doi.org/10.1158/0008-5472. CAN-10-3823

[13] IRIZARRY RA, HOBBS B, COLLIN F, BEAZER-BARCLAY YD, ANTONELLIS KJ et al. Exploration, normalization, and summaries of high density oligonucleotide array probe level data. Biostatistics 2003; 4: 249-264. https://doi.org/10.1093/ biostatistics/4.2.249

[14] DIBOUN I, WERNISCH L, ORENGO C, KOLTZENBURG M. Microarray analysis after RNA amplification can detect pronounced differences in gene expression using limma. BMC Genomics 2006; 7: 252. https://doi.org/10.1186/1471-2164-7$\underline{252}$

[15] LIU BH, YU H, TU K, LI C, LI YX et al. DCGL: an R package for identifying differentially coexpressed genes and links from gene expression microarray data. Bioinformatics 2010; 26: 2637-2638. https://doi.org/10.1093/bioinformatics/btq471

[16] KANEHISA M, GOTO S. KEGG: kyoto encyclopedia of genes and genomes. Nucleic Acids Res 2000; 28: 27-30. https://doi. org/10.1093/nar/28.1.27

[17] HUANG DW, SHERMAN BT, TAN Q, KIR J, LIU D et al. DAVID Bioinformatics Resources: expanded annotation database and novel algorithms to better extract biology from large gene lists. Nucleic Acids Res 2007; 35: W169-175.

[18] WINGENDER E, CHEN X, HEHL R, KARAS H, LIEBICH I et al. TRANSFAC: an integrated system for gene expression regulation. Nucleic acids research 2000; 28: 316-319. https:// doi.org/10.1093/nar/28.1.316

[19] SMOOT ME, ONO K, RUSCHEINSKI J, WANG P-L, IDEKER T. Cytoscape 2.8: new features for data integration and network visualization. Bioinformatics 2011; 27: 431-432. https://doi.org/10.1093/bioinformatics/btq675

[20] LIN Z, CHUANG WL, CHUANG YH. Amphotericin B up-regulates angiogenic genes in hepatocellular carcinoma cell lines. Eur J Clin Invest 2009; 39: 239-245. https://doi. org/10.1111/j.1365-2362.2008.02066.x 
[21] Alldinger S, Gr Ters S, Miao Q, Fonfara S, Kremmer E et al. Roles of an extracellular matrix (ECM) receptor and ECM processing enzymes in demyelinating canine distemper encephalitis. Dtsch Tierarztl Wochenschr 2006; 113: 151-152.

[22] DUENKER N, KRIEGLSTEIN K. Targeted mutations of transforming growth factor- $\beta$ genes reveal important roles in mouse development and adult homeostasis. Eur J Biochem 2000; 267: 6982-6988. https://doi.org/10.1046/j.1432-1327 2000.01825.x

[23] FARINATI F, CARDIN R, BORTOLAMI M, GUIDO M, RUGGE M. Oxidative damage, pro-inflammatory cytokines, TGF-alpha and c-myc in chronic HCV-related hepatitis and cirrhosis. World J Gastroenterol 2006; 12: 2065-2069. https:// doi.org/10.3748/wjg.v12.i13.2065

[24] IDOBE Y, MURAWAKI Y, KITAMURA Y, KAWASAKI H. Expression of transforming growth factor-beta 1 in hepatocellular carcinoma in comparison with the non-tumor tissue. Hepatogastroenterology 2003; 50: 54-59.

[25] SONG BC, CHUNG YH, KIM JA, CHOI WB, SUH DD et al. Transforming growth factor- $\beta 1$ as a useful serologic marker of small hepatocellular carcinoma. Cancer 2002; 94: 175-180. https://doi.org/10.1002/cncr.10170

[26] MAZZOCCA A, FRANSVEA E, LAVEZZARI G, ANTONACI S, GIANNELLI G. Inhibition of transforming growth factor $\beta$ receptor I kinase blocks hepatocellular carcinoma growth through neo-angiogenesis regulation. Hepatology 2009; 50: 1140-1151. https://doi.org/10.1002/hep.23118

[27] VAN ZIJL F, ZULEHNER G, PETZ M, SCHNELLER D, KORNAUTH C et al. Epithelial-mesenchymal transition in hepatocellular carcinoma. Future Oncol 2009; 5: 1169-1179. https://doi.org/10.2217/fon.09.91

[28] YUAN F, ZHOU W, ZOU C, ZHANG Z, HU H et al. Expression of Oct4 in HCC and modulation to wnt/ $\beta$-catenin and TGF- $\beta$ signal pathways. Mol Cell Biochem 2010; 343: 155-162. https://doi.org/10.1007/s11010-010-0509-3

[29] DESIDERIO MA. Hepatocyte growth factor in invasive growth of carcinomas. Cell Mol Life Sci 2007; 64: 1341-1354. https://doi.org/10.1007/s00018-007-7050-x

[30] MATSUMOTO K, NAKAMURA T. Hepatocyte growth factor and the Met system as a mediator of tumor-stromal interactions. Int J Cancer 2006; 119: 477-483. https://doi. org/10.1002/ijc. 21808

[31] JEANES A, GOTTARDI C, YAP A. Cadherins and cancer: how does cadherin dysfunction promote tumor progression\&quest. Oncogene 2008; 27: 6920-6929. https:// doi.org/10.1038/onc.2008.343

[32] HUANG F-I, CHEN Y-L, CHANG C-N, YUAN R-H, JENG Y-M. Hepatocyte growth factor activates Wnt pathway by transcriptional activation of LEF1 to facilitate tumor invasion. Carcinogenesis 2012; 33: 1142-1148. https://doi.org/10.1093/ carcin/bgs 131

[33] KRIEGL L, HORST D, REICHE JA, ENGEL J, KIRCHNER $\mathrm{T}$ et al. LEF-1 and TCF4 expression correlate inversely with survival in colorectal cancer. J Transl Med 2010; 8: 123. https:// doi.org/10.1186/1479-5876-8-123
[34] VADLAMUDI U, ESPINOZA HM, GANGA M, MARTIN DM, LIU X et al. PITX2, $\beta$-catenin and LEF- 1 interact to synergistically regulate the LEF-1 promoter. J Cell Sci 2005; 118: 1129-1137. https://doi.org/10.1242/jcs.01706

[35] SHI Y, WANG J, XIN Z, DUAN Z, WANG G et al. Transcription factors and microRNA-co-regulated genes in gastric cancer invasion in ex vivo. PLoS One 2015; 10: e0122882. https://doi.org/10.1371/journal.pone.0122882

[36] SUKHATME VP, CAO XM, CHANG LC, TSAI-MORRIS $\mathrm{CH}$, STAMENKOVICH D et al. A zinc finger-encoding gene coregulated with c-fos during growth and differentiation, and after cellular depolarization. Cell 1988; 53:37-43. https://doi. org/10.1016/0092-8674(88)90485-0

[37] BAEK SJ, KIM J-S, MOORE SM, LEE S-H, MARTINEZ J et al. Cyclooxygenase inhibitors induce the expression of the tumor suppressor gene EGR-1, which results in the up-regulation of NAG-1, an antitumorigenic protein. Mol Pharmacol 2005; 67: 356-364. https://doi.org/10.1124/mol.104.005108

[38] FAHMY RG, DASS CR, SUN LQ, CHESTERMAN CN, KHACHIGIAN LM. Transcription factor Egr-1 supports FGFdependent angiogenesis during neovascularization and tumor growth. Nat Med 2003; 9: 1026-1032. https://doi.org/10.1038/ $\underline{\text { nm905 }}$

[39] SUNG WK, ZHENG H, LI S, CHEN R, LIU X et al. Genome-wide survey of recurrent HBV integration in hepatocellular carcinoma. Nat Genet 2012; 44: 765-769. https:// doi.org/10.1038/ng.2295

[40] KAPOSI-NOVAK P, LEE JS, G MEZ-QUIROZ L, COULOUARN C, FACTOR VM et al. Met-regulated expression signature defines a subset of human hepatocellular carcinomas with poor prognosis and aggressive phenotype. J Clin Invest 2006; 116: 1582-1595. https://doi.org/10.1172/ JCI27236

[41] WAGNER EF, EFERL R. Fos/AP-1 proteins in bone and the immune system. Immunol Rev 2005; 208: 126-140. https:// doi.org/10.1111/j.0105-2896.2005.00332.x

[42] DAVEAU M, SCOTTE M, FRAN OIS A, COULOUARN C, ROS $\mathrm{G}$ et al. Hepatocyte growth factor, transforming growth factor $\alpha$, and their receptors as combined markers of prognosis in hepatocellular carcinoma. Mol Carcinog 2003; 36: 130-141. https://doi.org/10.1002/mc.10103

[43] FAN Q, HE M, DENG X, WU WK, ZHAO L et al. Derepression of c-Fos caused by MicroRNA-139 down-regulation contributes to the metastasis of human hepatocellular carcinoma. Cell Biochem Funct 2013; 31: 319-324. https://doi. org/10.1002/cbf.2902

[44] LIU T, HONG Y, TUNG K, YANG P. In silico and experimental analyses predict the therapeutic value of an EZH2 inhibitor GSK343 against hepatocellular carcinoma through the induction of metallothionein genes. Oncoscience 2016; 3: 9-20.

[45] TAKEDA S, LIU H, SASAGAWA S, DONG Y, TRAINOR PA et al. HGF-MET signals via the MLL-ETS2 complex in hepatocellular carcinoma. J Clin Invest 2013; 123: 3154-3165. https://doi.org/10.1172/JCI65566 


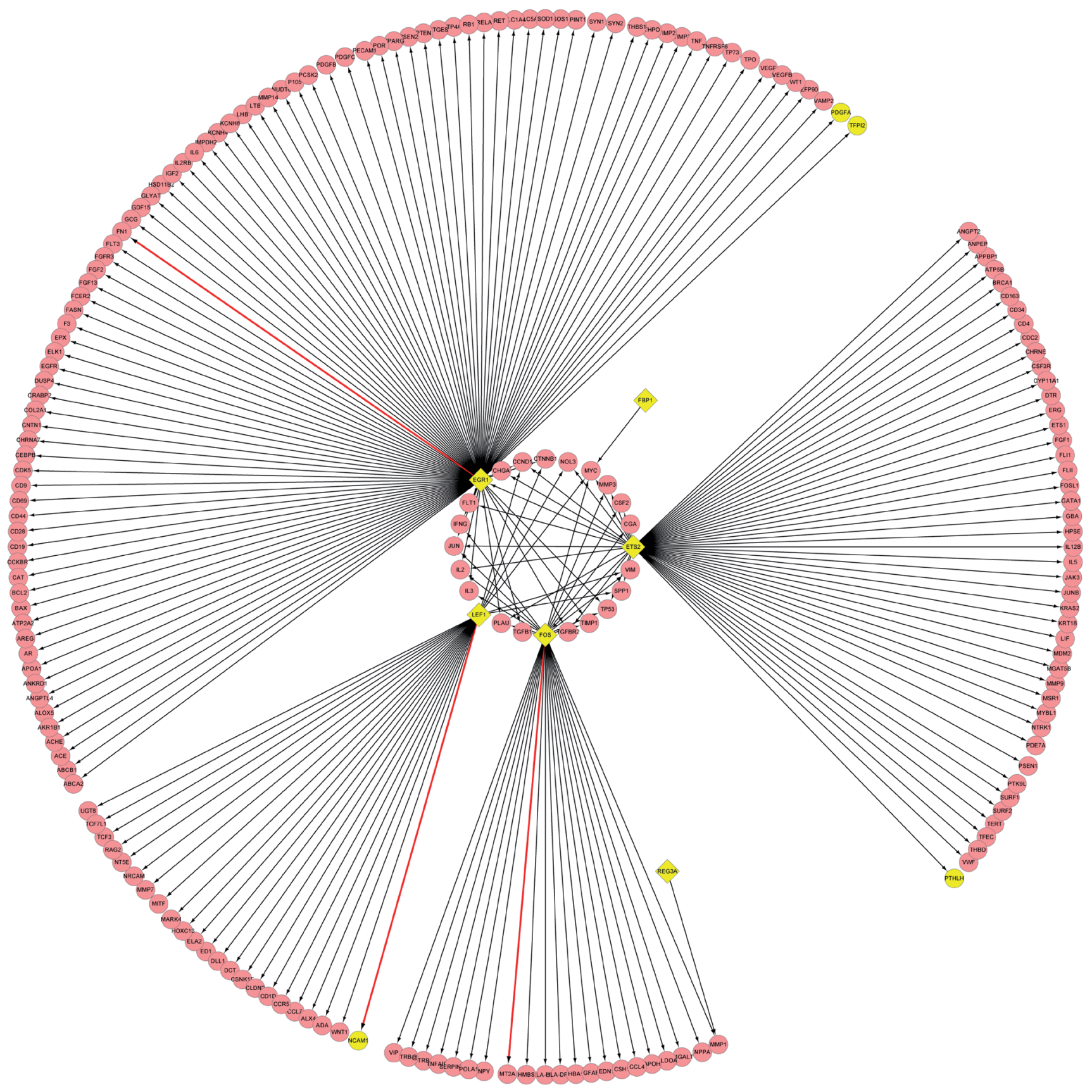

Supplementary Figure 1. Transcriptional regulation network diagram.

The six diamonds represent TFs, rounds denote target genes, and yellow dots represent the differentially co-expressed genes (DCGs), while pink dots represent the non-DCGs, red edges represent the three relations contained in differentially co-expressed links, while the black edges represent the known transcriptional regulation relations. 